Власенко И. Полихудожсественные основы симфонизащии танца. Статья посвящена выявлению полихудожественных факторов, которые питали идею симфонизации танца в начале ее становления. На примере «Лебединого озера» П. Чайковского выясняется иерархия элементов различных видов искусства в симфоническом танце. Определяется роль взаимодействия представителей разных творческих специальностей в процессе постановки симфонического танца.

Ключевые слова: полихудожественность, хореографическое образование, балет, симфонизация танца, классическая музыка.

Vlasenko I. Polyartistic basis of symphonization of the dance. The article is devoted to revealing polyartistic factors which had idea of symphonization of the dance in the beginning of its becoming. From an example of «Swan lake» by P. Tchaikovsky is found out hierarchy of elements of various kinds of art in symphonic dance. The role of interaction of representatives of different creative specialities during statement of symphonic dance is determined.

Keywords: polyartistry, choreographic education, ballet, symphonization of the dance, classical music.

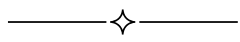

УДК $782.1+781.5$

\title{
A. Носуля
}

\section{ТЕМА ОЖИДАНИЯ В КАМЕРНЫХ ОПЕРАХ А. ШЕНБЕРГА И М. ТАРИВЕРДИЕВА}

Статья посвящена рассмотрению воплощения темы ожидания в камерных операх А. Шенберга и М. Таривердиева. Прослеживаются этапы эволюции и выделяются типы камерных оперных произведений, с усилением внимания к жанровому типу монооперы. Выделяются принципы и способы работы с музыкальным и литературным материалом в камерных операх.

Ключевые слова: камерная опера, моноопера, тема ожидания.

В современной музыковедческой и искусствоведческой литературе жанр камерной оперы выглядит сложившейся жанровой единицей, однако вопросы, связанные с ее жанровой спецификой до сих пор остаются недостаточно выясненными. Выдающийся исследователь Б. Асафьев называл оперу «чутким барометром интонационного строя эпохи» $[1$, с. 52], так как по чуткости и по подвижности средств 
драматургии и формы камерной опере нет равных среди иных жанровых форм. В ней заложены особые свойства мобильной реакции на различные общественные и художественные процессы, происходящие в социально-культурной сфере.

Достаточно подвижные границы жанровой разновидности камерной оперы вмещают в себя различные выражения соотношения музыки, драмы и сценического действия, что обусловило выделение нескольких типов камерной оперы - камерная музыкальная драма, камерная моноопера, синтетический камерный музыкальный спектакль. Каждый из обозначенных типов камерной оперы находится в непосредственной связи с традициями оперы большой формы, задействуя их в большей или меньшей степени. Наряду с этим, принципы формообразования и драматургического развития в различных типах камерной оперы находятся в непосредственной зависимости от сочетания специфических черт традиционной оперы и смежных музыкальных и театральных жанров.

Изучение различных этапов эволюции жанра камерной оперы приводит нас к выводу об усилении тенденции психологизации музыкально-драматического содержания произведения, происходящем на фоне его постепенного усложнения. Важно отметить, что на протяжении XX века камерная музыкальная драма и камерный музыкальный спектакль появлялись в творчестве различных композиторов, камерная моноопера, появившись в 1909 году в виде единственного образца - «Ожидания» А. Шенберга, - почти на полвека уступила место двум другим типам.

Сопоставление временных параметров традиционной и камерной опер выявляет значительное их различие, то есть время звучания текста камерной оперы значительно меньшее. Вместе с тем образно-драматургическая сфера не только не уступает традиционной опере, но и в ряде случаев более тонко и детально передает сложные психологические состояния или максимальный накал страстей. Исходя из этого, можно сделать вывод о наличии особого типа передачи музыкально-драматургического содержания - концентрированного и более уплотненного, по сравнению с традиционной оперой. Причем в каждом из обозначенных типов камерной оперы это происходит различно.

Так, в камерной музыкальной драме оно достигается благодаря уплотнению содержания драматического текста, более тщательному музыкальному его прочтению, следованию за каждой литературной 
интонацией. В синтетическом камерном музыкальном спектакле сочетаются две формы уплотнения и концентрированного изложения музыкально-драматургического содержания - уплотнение содержания на уровнях литературного текста и музыкального ряда. Концентрированное, уплотненное изложение на уровне литературного текста можно назвать уплотнением по горизонтали, а на уровне музыкального текста - по вертикали. В камерной моноопере форма складывается несколько отлично и, скорее, вызывает аналогию в отношении композиционных приемов с формами «чистой» музыки. Чаще всего музыкальный материал представлен в более обобщенном виде, некими образно-смысловыми синтагмами, где каждая становится выражением завершенного эпизода, пронизанного каким-либо одним эмоциональным состоянием. Важным аспектом строения композиционной формы является использование сквозной лейтинтонации, которая приобретает некий резюмирующий эффект, то есть сжимает и концентрирует передачу содержания эмоционального состояния посредством краткой мелодико-ритмической формулы.

Концентрированное изложение и уплотнение содержания камерного оперного произведения в первую очередь происходит на уровне словесного текста. Так при сокращении объема звучащего текста образно-смысловое содержание, а также психологическая и эмоциональная его составляющие существенно возрастают. Большое значение в подобного рода обобщениях имеет и более локальный характер конфликтов и идейно-образного содержания, типичный для камерной оперы. Известную роль играет здесь и отказ от внешних сценических эффектов в пользу напряженного внутреннего психологического развития драмы, переход конфликта из сферы конкретно-бытовой в обобщенно-символическую. Все это позволяет в еще большей мере сблизить трактовку оперы и «чистых» музыкальных жанров: с одной стороны, акцентировать типично оперные черты (еще плотнее «насытить» ее драматическим содержанием), с другой - трактовать оперную форму более обобщенно (по аналогии с формами в «чистых» музыкальных жанрах) [2].

Композиционно-драматургическое строение камерной моноопры находится в прямой зависимости от использования более сильных, по сравнению с достижениями оперного искусства прошлых веков, эмоциональных средств воздействия. Так, говоря об особенностях строения музыкальной речи одного из самых радикальных экспрессионистских сочинений А. Шенберга - монооперы «Ожи- 
дание», написанной в 1909 году, М. Тараканов указывает, что напряжение возникает «благодаря предельно концентрированному, ранее немыслимому в музыке насыщению каждой единицы музыкального времени» [4, с. 41]. Далее исследователь приходит к заключению, согласно которому в моноопере присутствует «лаконизм выражения каждого состояния, где порой достаточно тонкого штриха, чтобы обрисовать законченную картину», и «быстроту чередования отдельных контрастных состояний» [4, с. 41].

Само понятие моноопера указывает, в первую очередь, на оперное произведение, в котором имеется только одно действующее лицо. Такое сознательное ограничение демонстрирует сосредоточенность композитора и либреттиста на переживаниях, внутреннем мире и особых психологических (порой психических) состояниях одного человека. Уже в 1909 году А. Шенберг называет монодрамой оперу «Ожидание» с единственной героиней, а в 1984 году М. Таривердиев пишет свою монооперу «Ожидание», в которой снова единственным действующим лицом произведения оказывается «Она». Вряд ли идентичные названия можно объяснить простым совпадением, скорее это диалог двух композиторов (инициированный по понятным причинам М. Таривердиевым), двух эпох, а женщина с ее переживаниями и сложными эмоциональными состояниями оказывается неизменным объектом творческого внимания.

«Ожидание» А. Шенберга представляет собой огромный монолог героини, который отличается эмоциональной взвинченностью повествования и практически лишен сценического элемента. Именно отсутствие последнего стало препятствием для распространения в начале XX века оперы указанного типа, так как от жанра оперы попрежнему ожидали яркого сценического действа. Работа над произведением шла недолго, А. Шенберг написал «Ожидане» в течение двух недель. Либретто по просьбе композитора написала Мария Паппенхайм, которая по образованию была врачом, но пробовала свои силы в литературе. Точно установить, кто подал идею либретто и как проходила работа над ним, как считает Н. Власова, не представляется возможным. Определенно можно сказать, что Шенберг вносил в либретто существенные коррективы и что его исправления были направлены на то, чтобы «усилить мистическое и галлюцинаторное» [цит. по 3, с. 199]. Так, композитор убирает из текста либретто те фрагменты, где героиня конкретно описывает произошедшие события, сосредоточивая, таким образом, внимание слушателя не на 
событийном ряду, а на тех психологических состояниях и реакциях героини, которые являются ее реакцией на события.

Премьера «Ожидания» А. Шенберга состоялась в Праге лишь 6 июня 1924 года, и, хотя поначалу вызвала волну противоречивых отзывов, все же в историю музыки XX века произведение вошло как квинтэссенция музыкального экспрессионизма. Композитору удалось удивительно точно передать все эмоциональные состояния и духовные искания своего времени, ведь в период создания монодрамы экспрессионизм в Германии только начинался. «Ожидание» А. Шенберга отличают присущие искусству экспрессионизма черты: крайний субъективизм, порождающий бредовые видения, господство чувства страха и безысходности, которые воплощены в «Ожидании» в абсолютно чистом, концентрированном виде, что позволяет считать «Ожидание» «апофеозом шенберговской экспрессионистской эстетики» [цит. по 3, с. 200].

Сюжет монооперы А. Шенберга строится вокруг блуждающей по ночному лесу героини, которая с самого начала произведения пребывает в напряженном эмоциональном состоянии, а в ее болезненном воображении рисуются самые ужасные картины. В одном из писем сам композитор сравнивает эмоциональное состояние героини со страшным сном, и именно чувство страха является доминирующим во всем произведении. Таким образом, главной художественной задачей, которая стояла перед композитором, а впоследствии перед исполнительницей главной роли - передача эмоционального состояния страха, иными словами, развитие сценического действия практически отступает на задний план, а в центре произведения оказывается внутреннее, психическое состояние героини.

Слушатель становится свидетелем потока сознания героини, где звучат обрывки мыслей, оставленные без ответа и звучащие в никуда вопросы, вскрики, как реакция на нечто испугавшее героиню. Однако все, что поначалу кажется нездоровым бредом, находит свое страшное подтверждение, когда она находит труп своего возлюбленного. Это событие становится безусловным центром всего произведения и разделяет его на две части, разделительной чертой становится пауза в такте 158. Первая часть рисует состояния страха героини и ее предчувствия, вторая часть представляет собой монолог, адресованный и произнесенный над телом возлюбленного.

Большинство состояний героини и их описание композитором являются неоспоримым внедрением, проникновением в сферу бес- 
сознательного, что делает невозможным обсуждение и изучение данного произведения без затрагивания теории Зигмунда Фрейда, так как автор либретто Мария Паппенхайм косвенно имела к нему отношение. Во-первых, брат либреттистки Мартин Паппенхайм был психиатром и приверженцем теории 3. Фрейда, а их родственница Берта Паппенхайм лечилась непосредственно у самого Фрейда (именно она стала «героиней» его работы «Случай Анны О.») [3, с. 201-202]. Следовательно, работая над образом героини, либреттистка не могла обойти вниманием теорию фрейдовского психоанализа, и указанная теория была здесь как нельзя более кстати.

Функции текста и их соотношение с музыкальным материалом выстраиваются в произведении А. Шенберга совершенно особым образом, причем если ранее автору удавалось передавать столь напряженные состояния в довольно небольших фрагментах произведений, то, как указывает сам автор: «Несколько позже я обнаружил, как можно строить более протяженные формы, следуя [прозаическому] тексту или стихотворению. Различия в их размере и строении, смена характера и настроения отражались в строении и размере композиции, в ее динамике и темпе, фактуре и расстановке акцентов, инструментовке и оркестровке. В итоге разделы отграничивались один от другого так же ясно, как раньше благодаря тональным и формообразующим функциям гармонии»[6, с. 128]. Показательным моментом оркестровки особого типа становится факт отсутствия оркестровых сольных эпизодов, то есть вся оркестровая партия полностью подчинена главной идее произведения и ее главному выразителю - голосу.

Стремительная смена психологических состояний героини с музыкальной стороны характеризуется в резкой смене динамики, темпа изложения, подчеркнутой артикуляционной акцентуации. Композитор ради достижения необходимого эффекта, рисующего психологическое (и даже психическое) состояние героини, отказывается от любой тематической повторности и от излюбленного приема «возрастающей вариации». Как указывает Н. Власова, в «Ожидании» А. Шенберга происходящие события предельно сжаты во времени и практически наслаиваются одно на другое, «их экспонирование предельно сжато и сам принцип постоянного обновления становится конститутивным. Возможно, определенное влияние на композиционную технику здесь оказал живописный пуантилизм» [3, с. 203]. Кроме тематической сжатости, в монодраме выделяется два принципа работы с музыкальным материалом - принцип ясного тематического оформления, с неболь- 
шими завершенными построениями, и принцип атематического развития, материал которого состоит из резких музыкальных всплесков, вскриков, неожиданных резких ударов.

Если тематически оформленные разделы в основном связаны с более спокойной эмоциональной сферой и чаще всего воплощаются в звучании голоса, то атематические - связаны со сферой максимально аффектированных состояний, воссоздают приступы панического страха, и в таких фрагментах ведущим оказывается инструментальное звучание. При несомненном главенствующем начале речевого интонационного прототипа в вокальной партии в «Ожидании» А. Шенберга все же есть внутреннее членение на сугубо речитативные эпизоды и более распевные фрагменты, берущие свое начало в ариозной традиции.

Гармонический язык произведения достаточно самобытен, в его основе лежат квартовые аккорды, мелодический же план изобилует квартовыми и тритоновыми интонациями. Помимо этого, квартовые созвучия и тритоны выстраиваются и в более протяженные цепочки, образуя в некоторых случаях четырех-пятизвучия, а в кульминационном построении в такте 269 появляется десятизвучный аккорд, образованный квартовыми наслоениями. А. Шенберг в монодраме «Ожидание» довел до воплощения предельной ясности тенденцию детального показа психологических состояний и эмоций героини, опера становится «сейсмограммой», которая улавливает, преломляет, показывает «под увеличительным стеклом» сиюминутные нервные реакции [3, с. 214].

Моноопера М. Таривердиева «Ожидание», написанная в 1984 году и впервые поставленная театром Б. Покровского в 1985-м, становится продолжением философского размышления о судьбе женщины в современном мире. Тема ожидания, как особого эмоционального и психологического состояния, возникает в творчестве М. Таривердиева не случайно. Композитор уже не раз обращается в различных свои опусах к осмыслению тех непростых эмоциональных состояний, в которых пребывает современная женщина. М. Таривердиев говорил, что идея написания монооперы пришла к нему довольно рано, его очень привлекала эта идея, так как, собственно, все его вокальные циклы можно рассматривать как маленькие драмы. Не случайно он, увлекшись каким-либо отдельным стихотворением и тем эмоциональным откликом, которое оно вызывало в нем, подбирал другие сходные по духу стихотворения и выстраивал их в некое циклическое произведение. Поэтому в его творчестве практически не встречаются 
отдельные романсы, а только циклы, объединенные общей драматургической идеей и общим эмоциональным настроем. Таким образом, обращение к моноопере было закономерным и обусловленным более ранними произведениями композитора.

«Ожидание» М. Таривердиева, как и у А. Шенберга - это история женщины, раскрывающей все свои самые потаенные, сокровенные переживания, свои мысли и страхи. Снова присутствует некий возлюбленный, но в отличие от шенбергского довольно зловещего персонажа он предстает как некий довольно расплывчатый образ, который важен только как объект переживаний нашей героини. Эмоциональное состояние панического страха в этой моноопере практически не появляется, хотя испуг и страх за жизнь любимого здесь конечно присутствует.

Толчком для написания монооперы послужила встреча с Робертом Рождественским, в процессе которой поэт и композитор словно сделали устный набросок будущего произведения. Как указывает вдова композитора В. Таривердиева, обсуждение «включило обоих в процесс моментально. Как будто они обсуждали что-то, о чем уже неоднократно разговаривали, как будто у каждого внутри был уже готовый образ текста. Поняли друг друга с полуслова» [5]. Так возникла поэма «Ожидание. Монолог женщины» Р. Рождественского, изданная вскоре в журнале «Огонек», и на ее материале - моноопера «Ожидание». Простая и очень ясная поэтическая интонация Р. Рождественского, наличие ясной драматургической выстроенности, проявляющейся в смене контрастных состояний, наличии яркой кульминации и коды, дали возможность осуществиться давнему замыслу композитора. Текст поэмы был использован композитором не целиком, но зато был добавлен фрагмент одного из лирических, очень пронзительных стихотворений Рождественского «Как детство, ночь обнажена», который стал тихой лирической кульминацией монооперы. Как свидетельствует супруга композитора - замысел произведения вызревал долго, а осуществился в один момент: «Микаэл Леонович сел за рояль, поставил перед собой текст, диктофон и сыграл произведение от начала до конца. Потом, летом, в Сухуми, он записал партитуру и сделал клавир» [5].

Постановки монооперы проходили всегда с неизменным успехом, и главной отличительной чертой всех отзывов и рецензий был неизменный вопрос - как композитору удалось столь глубоко проникнуть во внутренний мир женщины и воссоздать его средствами музы- 
ки? Музыка оперы невероятно искренна и эмоциональна. Вместе с героиней мы переживаем всю шкалу эмоциональных состояний - от радостного волнения, через смущение, огорчение, взволнованность, страх - к философскому размышлению об одиночестве и его причинах. Композитор добивается раскрытия столь значительного диапазона различных психо-эмоциональных состояний при помощи удивительно мягкого и гибкого мелодизма, особой тембральной выверенности оркестрового сопровождения.

Таким образом, в монооперах А. Шенберга и М. Таривердиева с одноименным названием «Ожидание», при наличии ряда общих внешних предпосылок, музыкально-драматургическое воплощение существенно разнится. К общим чертам следует отнести наличие одной главной героини, сопереживание чувствам и волнениям которой и посвящено произведение; усиление тенденции психологизации музыкально-драматического содержания произведения, происходящее на фоне его постепенного усложнения. Так, концентрированное изложение и уплотнение содержания обеих моноопер происходит на уровне словесного текста. Так при сокращении объема звучащего текста образно-смысловое содержание, а так же психологическая и эмоциональная его составляющие существенно возрастают. Среди отличных черт произведений необходимо назвать принципиально разное видение критических эмоциональных состояний - у Шенберга это эмоции, граничащие с бредовыми и болезненными состояниями, у Таривердиева - это глубокая рефлексия, что находит отображение в музыкальном языке обеих моноопер.

\section{СПИСОК ЛИТЕРАТУРЫ}

1. Асафьев Б. Об опере / Б. Асафьев. - Л. : Музыка, 1976. - 334 с.

2. Басок М. Современная камерная опера. К проблеме специфики жанра : дис. ... канд. искусствоведения : 17.00.03 / М. Басок. - М., 1983. - 178 с.

3. Власова Н. Творчество Арнольда Шенберга / Н. Власова. - М. : ЛКИ, 2010. $-528 \mathrm{c}$.

4. Тараканов М. Музыкальный театр Альбана Берга / М. Тараканов. М. : Советский композитор, 1976-560 с.

5. Таривердиева В. Биография музыки / В. Таривердиева // Микаэл Таривердиев. Я просто живу. Вера Таривердиева. Биография музыки. - М. : Зебра E, $2004-$ C. $283-652$.

6. Schönberg A. Komposition mit zwölf Tönen // Schönberg A. Gesammelte Schriften I: Stil und Gedanke. Aufsätze zur Musik / Hrsg. von I. Vojtech. Frankfurt/ Main, 1976. 
Носуля А. Тема очікування у камерних операх А. Шенберга та М. Таривердіс$\boldsymbol{b a}$. Стаття присвячена розгляду втілення теми очікування у камерних операх А. Шенберга і М. Таривердієва. Простежуються етапи еволюції та виділяються типи камерних оперних творів, з посиленням уваги до жанрового типу моноопери. Виділяються принципи та методи роботи з музичним і літературним матеріалом в камерних операх.

Ключові слова: камерна опера, моноопера, тема очікування.

Nosulya A. Subject expectations the chamber opera A. Schoenberg and M. Tariverdiev. The article is devoted to the realization of the theme expectations chamber opera A. Schoenberg and M. Tariverdiev. Traced the stages of evolution and highlights the types of chamber operas, with increased attention to the genre type monoopera. Summarizes the principles and ways of working with musical and literary material in the chamber opera.

Keywords: chamber opera, monoopera, theme expectations.

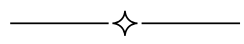

УДК $78.01+786.2$

\section{А. Езерская}

\section{ЖАНРЫ ФОРТЕПИАННОЙ МУЗЫКИ В ТВОРЧЕСТВЕ КОМПОЗИТОРОВ ХХ СТОЛЕТИЯ: К ВОПРОСУ О КАНОНИЧНОСТИ МУЗЫКАЛЬНОГО МЫШЛЕНИЯ}

Статья посвящена проблеме взаимодействия канонического и оригинального в системе музыкального творчества. В русле данной проблемы характеризуется место и значение фортепианных жанров в композиторском творчестве XX века. Сопоставляются принципы фортепианного мышления С. Прокофьева и Д. Шостаковича.

Ключевые слова: фортепианные жанры, жанровый канон, стилевой канон, музыкальное мышление, фортепианная поэтика.

Две методические черты фортепианного искусства XX века позволяют находить в нем особый предмет музыковедческого изучения. С одной стороны, фортепианная музыка академической традиции остается одной из наиболее устойчивых, можно сказать даже - консервативных жанровых сфер, соблюдая, прежде всего, все правила построения больших и малых циклических форм, сохраняя приоритеты таких композиционных структур, как сонатное аллегро и миниатюра. С другой - фортепианное творчество чаще иных органологических и

(C) Езерская А., 2014 